\title{
Mémoire et oubli
}

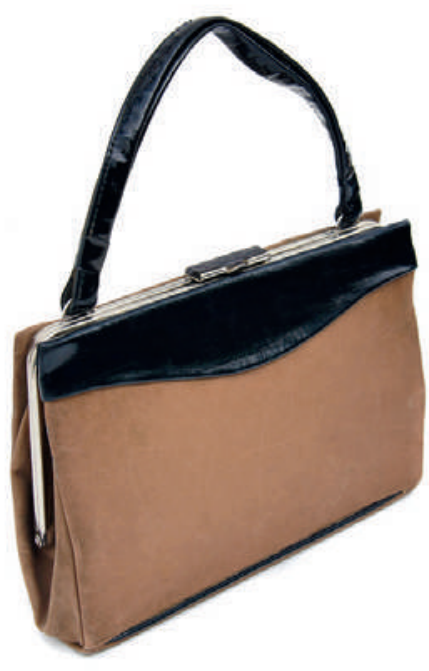

«Chacun a le droit de penser ce qu'il veut», chante le groupe de patients de l'établissement médico-social allemand de Duisbourg. Pas vraiment le foyer médicalisé que l'on pourrait souhaiter pour la dernière partie de sa vie. Dans une telle situation, laisser divaguer ses pensées peut faire du bien. Je sais par expérience à quel point, dans un contexte inhospitalier, un exercice de ce type peut libérer les sentiments refoulés.

La patiente, Mme Mauerhoff, tente de chanter avec les autres. Mais ses pensées ne sont plus libres, elle ne peut plus se dégager de ses soucis. Mme Mauerhoff souffre de démence et sa maladie est à un stade moyen, très douloureux et angoissant pour elle, où souvenirs récents et moyennement anciens disparaissent.

Eva Mauerhoff est le personnage principal du documentaire primé «Une journée disparue dans le sac à main» [1], réalisé en 2000 par Marion Kainz. Ce film impressionnant de compassion suit Mme Mauerhoff désorientée, confuse et angoissée, au fil de ses errances à travers les couloirs, à la recherche de la sortie. «N'y a-t-il nulle part où je puisse demander si on me connaît, pour que je puisse avoir des points de repères», demande-t-elle, l'air hagard. Elle veut rentrer chez elle mais ne sait pas où c'est, elle ne se souvient plus de son domicile et recherche la dernière journée dans son sac à main. Mme Mauerhoff est prisonnière des frontières de plus en plus resserrées que lui impose son propre cerveau.

La démence est actuellement au cœur des débats. La librairie par correspondance, Mabuse, en Allemagne, spécialisée dans les ouvrages médicaux, y consacre par exemple trois cents titres. Elle est présente dans les romans, comme dans celui de Martin Suter «Small World», et dans les films, comme récemment dans «Vergiss mein nicht» de David Sieveking. Le thème est aux confins de la médecine, des sciences humaines et de la sociologie. Dans la paroisse de l'église Enge, à Zurich, récemment, des professionnels étaient invités par la SGKW à débattre des aspects de la démence, du souvenir et de l'oubli, en s'appuyant sur le documentaire de M. Kainz.

Pour le spécialiste de la littérature Rudolf Käser (université de Zurich) cette importante couverture médiatique trahit aussi la peur de la maladie. Et pour Albert Wettstein, vice-président de l'Association Alzheimer du canton de Zurich, et ancien médecin de ville à Zurich, cette approche de la maladie du point de vue des sciences humaines contribue à développer un langage permettant de gérer les difficultés et de les traiter.

La démence est aussi pour nous une source d'angoisse car elle détruit un aspect de plus en plus important à l'heure actuelle: contrôler l'existence.
On perd la maîtrise de soi et de sa vie, son orientation, donc son autonomie et sa liberté. La mémoire, de plus en plus altérée par la démence, est un élément fondamental sur lequel ces valeurs sont basées.

«Quel jour sommes-nous aujourd'hui?» Pour A. Wettstein, il y a quelque temps on cherchait à combattre l'oubli grâce à des exercices ancrés dans la réalité, ce qui ne faisait qu'augmenter l'agitation des patients. R. Käser estime que c'est aussi ce que reflète le type de documentaire de M. Kainz, dans lequel Alzheimer est représenté comme des sortes de «limbes». Maintenant, les soignants cherchent plutôt à familiariser les personnes touchées avec leur environnement: les patients devraient avoir assez de temps pour s'habituer à un nouveau domicile. La notion de familier résulte de références émotionnelles: lieux, visages, relations, contacts. Les chansons qui sont ancrées suffisamment profond dans la mémoire peuvent aussi créer une sensation de familiarité. Albert Wettstein conseille de rendre régulièrement visite aux patients, d'annoncer sa prochaine visite et de leur offrir une photo de soi.

Bien souvent, la sensation de familier ne peut se passer d'une partie de la mémoire basique, qu'il s'agisse des visages, des voix ou des odeurs. Ce n'est que dans la dernière phase de la maladie que les personnes vivent exclusivement dans le présent.

\section{Le grand oubli n'a pas que des inconvénients.}

Le grand oubli n'a pas que des inconvénients. Pour Elisabeth Flach, conseillère spirituelle du centre médico-social d'Entlisberg: «Les patients se libèrent de certains freins et inhibitions et le comportement des personnes change fortement. Il y a une plus grande proximité, elles sont plus accessibles, notamment par le biais des chansons, des rituels et des prières.»

Un bénéfice secondaire de la maladie. Pour R. Käser, la nouvelle image de la démence se reflète aussi dans les médias, comme en témoigne le film «Vergiss mein nicht». Moins d'angoisse et plus de perspectives?

Eberhard Wolff*

1 www.der-tag-der-in-der-Handtasche-verschwand.de (en allemand) 